\title{
Making communication and resolution programmes mission critical in healthcare organisations
}

\author{
Thomas H Gallagher (D) ,' Richard C Boothman, ${ }^{2}$ Leilani Schweitzer, ${ }^{3}$ \\ Evan M Benjamin ${ }^{4}$
}

'Department of Medicine, University of Washington, Seattle, Washington, USA ${ }^{2}$ Boothman Consulting Group, LLC, Ann Arbor, Michigan, United States

${ }^{3}$ The Risk Authority, Stanford Medicine, Palo Alto, CA, United States

${ }^{4}$ Ariadne Labs, Harvard School of Public Health and Brigham \& Womens Hospital, Boston, MA, United States

\section{Correspondence to}

Dr Thomas H Gallagher, Department of Medicine, University of Washington, Seattle, WA 98040, USA; thomasg@uw.edu

Accepted 15 April 2020 Published Online First 5 May 2020

\section{SLinked}

- http://dx.doi.org/10.1136/ bmjqs-2019-010367

- http://dx.doi.org/10.1136/ bmjqs-2019-010296

\section{Check for updates}

(c) Author(s) (or their employer(s)) 2020. No commercial re-use. See rights and permissions. Published by BMJ.

To cite: Gallagher TH, Boothman RC, Schweitzer L, et al. BMJ Qual Saf 2020:29:875-878.
Patients entrust their lives to healthcare providers. Healthcare providers, in turn, aim to promote wellness, heal what can be healed and relieve suffering, all with comfort and compassion. Yet, when patients are harmed by their healthcare, too often they experience defensiveness and disregard that actually exacerbates their suffering, adding insult to injury. ${ }^{12}$ Communication and resolution programmes (CRP) can mitigate this further harm and avoid pouring salt on the wounds of patients whom the healthcare system has hurt instead of helped. These programmes strive to ensure that patients and families injured by medical care receive prompt attention, honest and empathic explanations, sincere expressions of reconciliation including financial and non-financial restitution, and reassurance from efforts to prevent future harm to others. ${ }^{3}$ Decades of study and interest in CRPs seem to be resulting in increased implementation with the hope that supporting patients, families and caregivers after harm could become the norm rather than the exception. ${ }^{4}$

Yet a central problem looms, and unless effective solutions are enacted, the potential of CRPs may go largely unrealised. The field is rife with inconsistent implementation, which often reflects a selective focus on claims resolution rather than a fully implemented ('authentic') $\mathrm{CRP}^{5}{ }^{5}$ Inconsistent CRP implementation means that fewer patients and families benefit from this model and opportunities for improving quality and safety are missed. Authentic CRPs, in contrast, are comprehensive, systematic and principled programmes motivated by fundamental culture change which prioritises patient safety and learning. In an authentic CRP, honesty and transparency after patient harm are viewed as integral to the clinical mission, not as selective claims management devices. ${ }^{6}$ CRPs appear to improve patient and provider experiences, patient safety, and in many settings lower defence and liability costs in the short term and improve peer review and stimulate quality and safety over time. ${ }^{7-10}$ While the claims savings often associated with a CRP are welcome, authentic CRPs focus on a more ambitious goal: fostering an accountable culture. Nurturing accountability produces better and safer care which serves the overall clinical mission, happily accomplishing more durable claims reduction along the way.

Two thoughtful papers in this issue of BMJ Quality \& Safety highlight barriers to effective CRP implementation and offer important insights to aid in the spread of this critical model. ${ }^{11}{ }^{12}$ Below we outline four suggested strategies for realising the vision of authentic CRPs.

\section{STRATEGY 1: MAKE CRPS A CRITICAL ORGANISATIONAL PRIORITY GROUNDED IN THE CLINICAL MISSION}

The most important cause of inconsistent CRP implementation is the failure of institutional leaders, including boards and senior executives ('C-suites'), to recognise them as a mission-critical component of modern healthcare. As a result, even at organisations professing to embrace accountability and transparency after patient harm, CRPs rarely receive overt leadership support or the resources and performance expectations associated with other mission-critical initiatives. ${ }^{13}$

The reasons why CRPs have not been elevated to mission-critical status at healthcare organisations are complex. Competing and distracting clinical and 
financial priorities abound. But a central challenge that has hampered CRPs is the tendency of many C-suites to rely on their liability insurance, risk and legal partners to direct the response to injured patients. Neither the insurance industry nor the legal profession naturally shares the same values and mission as healthcare organisations. ${ }^{14}$ Healthcare leaders need to insist that responses to injured patients align with their organisations' clinical missions. In the absence of such C-suite insistence, 'deny and defend' will remain the dominant response to injured patients.

This C-suite deference to the claims expertise of the insurance industry and legal profession has additional causes, including: (A) resignation that unintended adverse outcomes will happen even with reasonable care; (B) acceptance of litigation as unavoidable and a cost of doing business; (C) reluctance of chief executive officers/board members (who are not trial lawyers) to challenge worst-case scenarios painted by defence lawyers and insurance claims professionals; and (D) human nature that avoids confrontation and exaggerates the potential challenges of dealing with injured patients. These factors inform the attitude of some health systems that no adverse events deserve compensation and that the caregivers/organisations are the real victims.

While it is encouraging to see a few large liability insurers developing CRPs and even incentivising their adoption, ${ }^{15}$ more insurers are engaging with CRPs as passive observers, with others remaining actively opposed. Insurers and attorneys will align as CRP partners only when healthcare organisations identify CRPs as a mission-critical priority.

\section{STRATEGY 2: COMPEL INSTITUTIONAL LEADERS TO RECOGNISE THE CRITICAL IMPORTANCE OF CRPS}

What would persuade boards and C-suites to prioritise a CRP? The study by Prentice et al suggests the answer lies in making institutional leaders recognise the necessity of CRPs through engagement with injured patients and their families. ${ }^{11}$

Prentice and colleagues report the first truly population-based assessment of the impact of medical errors on patients. Their results highlight the continuing emotional toll that patients and their families suffer from preventable injuries. On an encouraging note, they also document the potential that open and honest communication has for reducing emotional harm. While over half of the patients who reported experiencing medical errors 3-6years ago described at least one emotional impact from the event, those who reported the greatest degree of open communication with healthcare providers after an error were less likely to experience persisting sadness, depression or feelings of abandonment and betrayal. Open and honest communication after an error also predicted less doctor/facility avoidance.
When boards and C-suites acknowledge the additional emotional harm inflicted on injured patients and their families (not to mention staff) when a CRP is not used or is poorly implemented, the missioncritical nature of CRPs will become paramount. ${ }^{16}{ }^{17}$ The emotions of patients and families who have been harmed can be complex, intense and intimidating. ${ }^{18}$ It has been all too easy for board members and senior executives to look away and avoid direct involvement when their organisations harm the very patients they exist to serve. Patients and their families, of course, cannot enjoy the luxury of looking away. ${ }^{19}$

While boards are sometimes made aware of selected high-value harm events, these cases represent only the tip of the iceberg. Cases of patient harm that are less than catastrophic are rarely shared with boards, but represent a large reservoir of patient and family suffering as well as opportunities for learning. Many patients who experience injuries hesitate to complain, fearing their ongoing care may be adversely affected. ${ }^{20} 21$ Patients who have experienced serious harm may have difficulty garnering representation from a qualified plaintiff attorney especially if their claim is deemed to be worth under $\$ 500000$. Boards aware only of a few high-value cases will fail to appreciate the magnitude of harm caused by substandard care and falsely believe that their organisation is responding optimally to the few they know about.

Engaging a patient as soon as possible after an unplanned clinical event is a CRP hallmark. Listening, with the explicit goal of understanding the experiences of patients and families who have been harmed, is invaluable to any organisation striving for patient centricity and generates insights not available to 'deny and defend' adherents. Partnering with patients who have had unplanned clinical outcomes changes the way healthcare organisations value informed consent, transitions of care and communication in general. As patient engagement is normalised across organisations, boards and C-suites will readily recognise the importance to their clinical mission and the value of the return on investment in the CRP model beyond financial gains. The accountable culture which emerges has the potential to generate other benefits unthinkable in a defensive environment: improved staff morale with better staff retention, an open environment which values speaking up for safety, accelerated and more effective clinical outcomes and evidence-based peer review, to name a few.

\section{STRATEGY 3: INVEST IN CRP IMPLEMENTATION TOOLS AND RESOURCES}

Equating CRPs to early claims resolution predictably yields inconsistent and selective application of the model and, worse, a failure to realise its full potential for cultural improvement. ${ }^{22}$ Even as boards and C-suites accept the mission-critical status of CRPs (the 'why'), they may not appreciate the importance of the 'how'. 
The second CRP-related paper in this issue of $B M J$ Quality and Safety emphasises how successful CRPs rely on the development of systems and standard work to promote consistent application. ${ }^{12}$ Mello and colleagues describe the work of the Massachusetts Alliance for Communication and Resolution after Medical Injury (MACRMI) and articulate the most important elements of their success to date. Their findings reinforce other papers that emphasize the critical nature of having the right people, processes and systems in place. ${ }^{23}$

One essential element of the MACRMI model is the commitment to a process of reviewing unplanned clinical outcomes eligible for a CRP approach. Normalising a triaged review and then faithfully using the CRP for all eligible cases, regardless of whether that case might become a claim, allows the CRP to meet patient, family and caregiver needs, as well as to drive process improvements faster on a much broader group of harm events. This systematic approach to case selection also demonstrates to clinical audiences that the CRP is not premised primarily on saving money, but is a norm expected within the clinical mission.

The MACRMI experience also highlights the importance of devoting sufficient resources to planning and executing a CRP. Many organisations focus most of their CRP efforts around training different teams to enact key steps in the CRP process. While trainings may be a necessary element, reproducible workflows and simple tools are far more important. With clear leadership support, these tools and processes must be developed with and by the people in the organisation who will actually use them, rather than imposing approaches that may have worked in another system that is organised differently. Organisations should understand that potential litigation is an ever-present reality. Sometimes, despite the CRP's principled assessment and engagement, reasonable minds may still differ, and in a small minority of cases litigation is required. Because the motivation for CRPs is to instil the accountable culture required for continual clinical improvement, success cannot be contingent on erasing the threat of litigation altogether.

Finally, a significant element of MACRMI's success involved a shared learning community in which organisational leaders and key managers came together to discuss CRP cases supported by unfiltered patient experiences, clinical and patient safety findings and measures of implementation. The community acquired a moral authority which encouraged accountability, consistent application of CRP principles, and ultimately demonstrated broad results of the favourable impact on patients, providers, system learning and liability costs.

\section{STRATEGY 4: DEPLOY CRP METRICS TO GOVERN CRP AND TRACK PROGRESS}

Metrics matter; organisations measure what they deem important. ${ }^{5}$ At present it is rare that organisations know how many unintended clinical events occurred in the previous year, how many of the affected patients and families were treated with honesty and transparency, how many of those deemed worthy of compensation actually received it, how many of the affected providers received care, or how many of those cases resulted in clinical improvements. The absence of these data makes it nearly impossible to assign appropriate leadership accountabilities for CRPs and to understand how well a CRP is functioning in service to the organisational mission. Measuring mainly claims and costs signals a preoccupation with money, not continual clinical improvement, and certainly not patient centricity or care for the caregiver workforce. A comprehensive suite of national CRP measures is currently being developed and refined jointly by the Collaborative for Accountability and Improvement and Ariadne Labs, and should be ready for widespread dissemination by the end of this year.

\section{CLOSING}

Healthcare organisations exist to serve with compassion and clinical excellence the patients and their families who entrust them with their lives. Our society expects no less; the privilege of delivering healthcare, a practice that is intrinsically dangerous, carries a heavy responsibility to minimise the risk of harm. When patients are harmed, CRPs honour patients' trust and caregivers' selfless dedication with honesty, transparency, best efforts at reconciliation for all and relentless determination to improve. One thing is clear: shedding 'deny and defend' in favour of a transition to an authentic CRP undoubtedly requires leadership from boards and C-suites focused on their organisations' clinical mission. If healthcare organisations are sincere in striving to attain their clinical goals, they will insist on nothing less than elevating their CRPs to mission-critical status and using the requisite tools and resources to ensure consistent application of this model.

\section{Twitter Thomas H Gallagher@TGallagherUW}

Acknowledgements Many thanks to Gary S Kaplan, MD, for contributing to the concepts presented in this paper, and to Paulina H Osinska, MPH, for her assistance with manuscript preparation.

Funding Supported by generous donations from John Laurence Adams and the Joan Grillo Adams Memorial Fund, the Ullem Foundation, and the Family of Glenn E Clarkson.

Competing interests None declared.

Patient consent for publication Not required.

Provenance and peer review Commissioned; internally peer reviewed.

\section{ORCID iD}

Thomas H Gallagher http://orcid.org/0000-0001-8323-1450

\section{REFERENCES}

1 Iedema R, Allen S, Britton K, et al. Patients' and family members' views on how clinicians enact and how they should enact incident disclosure: the "100 patient stories" qualitative study. BMJ 2011;343:d4423. 
2 Moore J, Mello MM. Improving reconciliation following medical injury: a qualitative study of responses to patient safety incidents in New Zealand. BMJ Qual Saf 2017;26:788-98.

3 Collaborative for accountability and improvement. CRP essentials, 2017. Available: http://communicationandreso lution.org/pix/Collaborative_CRP_Essentials.pdf

4 McDonald TB, Van Niel M, Gocke H, et al. Implementing communication and resolution programs: lessons learned from the first 200 hospitals. J Patient Saf Risk Manag 2018;23:73-8.

5 Gallagher TH, Mello MM, Sage WM, et al. Can Communication-And-Resolution programs achieve their potential? five key questions. Health Aff 2018;37:1845-52.

6 Boothman RC, Blackwell AC, Campbell DA, et al. A better approach to medical malpractice claims? the University of Michigan experience. J Health Life Sci Law 2009;2:125-59.

7 Mello MM, Kachalia A, Roche S, et al. Outcomes in two Massachusetts Hospital systems give reason for optimism about Communication-And-Resolution programs. Health Aff 2017;36:1795-803.

8 Kachalia A, Kaufman SR, Boothman R, et al. Liability claims and costs before and after implementation of a medical error disclosure program. Ann Intern Med 2010;153:213-21.

9 Lambert BL, Centomani NM, Smith KM, et al. The "Seven Pillars" Response to Patient Safety Incidents: Effects on Medical Liability Processes and Outcomes. Health Serv Res 2016;51 Suppl 3:2491-515.

10 LeCraw FR, Montanera D, Jackson JP, et al. Changes in liability claims, costs, and resolution times following the introduction of a communication-and-resolution program in Tennessee. J Patient Saf Risk Manag 2018;23:13-18.

11 Prentice JC, Bell SK, Thomas EJ, et al. Association of open communication and the emotional and behavioural impact of medical error on patients and families: state-wide crosssectional survey. BMJ Qual Saf 2020;29:883-94.
12 Mello MM, Roche S, Greenberg Y, et al. Ensuring successful implementation of communication-and-resolution programmes. BMJ Qual Saf 2020;29:895-904.

13 Daley Ullem E, Gandhi TK, Mate K, et al. Framework for effective board governance of health system quality. Boston, Massachusetts: Institute for Healthcare Improvement, 2018.

14 Sage WM. The forgotten third: liability insurance and the medical malpractice crisis. Health Aff 2004;23:10-21.

15 BETA Healthcare Group. Beta heart, 2020. Available: https:// www.betahg.com/risk-management-and-safety/beta-heart/

16 Hemmelgarn C. Seeking answers, hearing silence. Health Aff 2018;37:1332-4.

17 Clarkson MD, Haskell H, Hemmelgarn C, et al. Abandon the term "second victim". BMJ 2019;364:11233.

18 Moore J, Bismark M, Mello MM. Patients' experiences with Communication-and-Resolution programs after medical injury. JAMA Intern Med 2017;177:1595-603.

19 Gallagher TH, Waterman AD, Ebers AG, et al. Patients' and physicians' attitudes regarding the disclosure of medical errors. JAMA 2003;289:1001-7.

20 Mazor KM, Roblin DW, Greene SM, et al. Toward patientcentered cancer care: patient perceptions of problematic events, impact, and response. J Clin Oncol 2012;30:1784-90.

21 Fisher K, Smith K, Gallagher T, et al. We want to know: eliciting hospitalized patients' perspectives on Breakdowns in care. J Hosp Med 2017;12:603-9.

22 Mello MM, Boothman RC, McDonald T, et al. Communication-and-resolution programs: the challenges and lessons learned from six early adopters. Health Aff 2014;33:20-9.

23 Hickson GB, Moore IN, Pichert JW, et al. Balancing systems and individual accountability in a safety culture. In: Berman S, ed. From front office to front line. Oakbrook Terrace, IL: Joint Commission Resources, 2012: 1-36. 